Article

\title{
Understanding Chinese Consumers' Intention to Purchase Sustainable Fashion Products: The Moderating Role of Face-Saving Orientation
}

\author{
Xiaoyong Wei and Sojin Jung * \\ Institute of Textiles and Clothing, The Hong Kong Polytechnic University, Hong Kong, China; \\ felix.wei@connect.polyu.hk \\ * Correspondence: sojin.jung@polyu.edu.hk; Tel.: +852-3400-3094
}

Received: 19 July 2017; Accepted: 30 August 2017; Published: 12 September 2017

\begin{abstract}
In a culture where collectivism is pervasive such as China, social norms can be one of the most powerful tools to influence consumers' behavior. Individuals are driven to meet social expectations and fulfill social roles in collectivist cultures. Therefore, this study was designed to investigate how Chinese consumers' concern with saving face affects sustainable fashion product purchase intention and how it also moderates consumers' commitment to sustainable fashion. An empirical data set of 469 undergraduate students in Beijing and Shanghai was used to test our hypotheses. Results confirmed that face-saving is an important motivation for Chinese consumers' purchase of sustainable fashion items, and it also attenuated the effect of general product value while enhancing the effect of products' green value in predicting purchasing trends. The findings contribute to the knowledge of sustainable consumption in Confucian culture, and thus their managerial implications were also discussed.
\end{abstract}

Keywords: face-saving; Chinese consumers; perceived value; green value; sustainable consumption

\section{Introduction}

With China's emerging economy, its consumer market is expanding rapidly. Particularly in the fashion industry, China's 1.3 billion people constitute a huge market for garment consumption [1]. According to Euromonitor [2], China was the second largest market for apparel and footwear, which generated a total retail value of USD 328,389.4 million in 2016, and is expected to experience a 3\% growth rate over the next two years. In spite of this huge potential, the fashion industry has caused serious environmental problems in China such as water pollution [3]. To resolve the sustainability issue, the Chinese government has transformed each of the Sustainable Development Goals (SDGs) into action plans based on its recent national plan to implement the UN 2030 agenda for sustainable development [4]. Additionally, an increasing number of fashion consumers have been paying attention to issues of sustainability in fashion for future development in China [5].

Previous research has shown that purchases of sustainable products are driven by consumers' altruism [6-8], as well as self-benefit motives (e.g., status seeking) [9,10]. In a culture where collectivism is pervasive such as in China, social norms were found to be powerful in determining consumers' behavior [11,12], and Chinese consumers' orientation to save face (i.e., face-saving) through following social norms is one of important motivations guiding their purchasing behavior [11]. The concept of face refers to an individual's public self-image [13], which can be gained or lost in social interactions. For example, individuals can gain face through demonstrating behavior that meets social expectations and fulfills accepted social roles, and they can lose face when they are not treated respectfully [12]. Thus, an individual concerned with face-saving would be inclined to make choices toward maintaining a good public self-image. Because fashion products tend to be publicly consumed [14], choosing 
sustainable fashion items may be closely related to public image enhancement in China [15]. However, there is still a lack of empirical evidence to demonstrate whether or not Chinese consumers' sustainable fashion consumption is influenced by face-saving impulses. Therefore, this study aimed to test whether Chinese consumers' sustainable fashion product purchase intention is driven by face-saving efforts through empirical data. We posited that consumers who are highly concerned with face-saving are more likely to purchase sustainable fashion products because the consumption of such products can build and maintain a good public image (i.e., save face).

Keller's customer-based brand equity [16] and consumption value theory $[17,18]$ argues that there are three types of perceived values attached to general consumer products: functional, emotional and social. For sustainable products, the "green" value, which satisfies consumers' environmental concerns, was also studied [19]. Thus, this study was built on the three types of values generally related to products (i.e., general product value), as well as the green value specifically related to sustainable products, and was designed to answer the following questions: (1) how these values and face-saving orientation increase a consumer's commitment to sustainable fashion, and; (2) how Chinese consumers' face-saving orientation moderates the effect of each value toward this commitment.

The findings of this study contribute to a body of knowledge on perceived value studies by examining the role of a cultural factor, face-saving, in the relationship between perceived value and sustainable fashion product purchase. Moreover, this study was the first attempt to empirically test the effect of face-saving on Chinese consumers' sustainable product purchase, which addresses an important cross-cultural issue regarding sustainable consumption. Our findings also reveal essential managerial implications for fashion companies by giving them an understanding of Chinese consumers' perceptions.

\section{Literature Review}

\subsection{Sustainable Fashion and Consumer Purchase Intention}

The sustainable fashion issue has been widely discussed in marketing studies, and a number of similar terms were found in the literature including ethical fashion, green fashion, eco-fashion and so forth (Table 1). As the triple bottom line argues for social and environmental goals for sustainable development (i.e., economic goal) [20], sustainable fashion and similar terms incorporated environmental and social aspects of sustainability, as seen in Table 1. For example, the environmental goals were stated by terms "organic" [21,22], "biodegradable" [22], and "eco-labelled or recycled material" [23], and social goals were indicated by terms "fair trade" [21,22], "sweatshop-free labor conditions" [22], and "locally" [23]. However, green fashion mainly refers to environmental sustainability [24]. Based on a literature review, we define sustainable fashion as fashion products that benefit, or at least do not harm, our environment and society in their production and consumption processes, and contribute to creating a sustainable future of human beings. For example, fashion products produced using chemicals that minimize environmental hazards, fabrics such as organic cotton, recycled materials, sweatshop-free labor, fair trade, or for products made for long-term use, all can be deemed sustainable fashion.

Although sustainable fashion is a broad concept including many aspects of production and consumption process [25], this study focused on the consumption side, especially the intention to purchase sustainable fashion products because we surveyed consumers. Understanding consumers' purchase intention would be very important to develop business strategies and enhance sustainability in that purchase preference is the direct consequence of companies' value delivery activities (i.e., marketing) [19], and consumers' purchase preference would facilitate companies' improvement on their sustainable performances [26]. 
Table 1. Literature on the concepts of sustainable fashion.

\begin{tabular}{clcc}
\hline \multicolumn{1}{c}{ Term } & \multicolumn{1}{c}{ Description } \\
\hline Sustainable clothing & $\begin{array}{l}\text { SClothing which incorporates one or more aspects of social and environmental } \\
\text { sustainability, such as Fair Trade manufacturing or fabric containing } \\
\text { organically-grown raw material" (p. 938). }\end{array}$ \\
\hline Ethical fashion & $\begin{array}{l}\text { "Fashionable clothes that incorporate fair trade principles with sweatshop-free } \\
\text { labor conditions while not harming the environment or workers by using } \\
\text { biodegradable and organic cotton" (p. 361). }\end{array}$ \\
\hline Eco-fashion & $\begin{array}{l}\text { "Clothing that is designed for lifetime use; it is produced in an ethical system, } \\
\text { perhaps even locally; it causes little or no environmental impact and it makes use } \\
\text { of eco-labelled or recycled materials" (p. 152). }\end{array}$ \\
\hline Green fashion & $\begin{array}{l}\text { "The green [fashion] concept is related to the ecological dimension of sustainable } \\
\text { development" (p. 67). }\end{array}$ \\
\hline Sustainable fashion & $\begin{array}{l}\text { "Sustainable fashion encompasses the myriad of issues of an ethical or } \\
\text { environmental nature in the production and consumption of fashion" (p. 150). }\end{array}$ \\
\hline
\end{tabular}

\subsection{Face-Saving}

Face reflects individual's place in the social network, and is an important value in Confucian culture. As defined by Brown \& Levinson [13], face is an individual's public self-image, and face can be gained or lost in social interactions. People can gain face if they demonstrate behavior that meets social expectations and fulfills social roles, and may lose face if they are not treated respectfully due to exhibiting behavior that deviates from social norms and expectations [12]. Although face originated from Confucian culture such as in China, it is also a universal human need [27] in that people try to maintain a good public self-image, which is consistent with efforts to save face. Ho [27] compared the concept of face with prestige. He argues that to achieve prestige, one must demonstrate his ability to earn respect from others, but having face may not require such efforts. For example, the son of a famous person can have face by taking a prominent place in society, but without any proof of his own abilities, he may have little or no prestige. Having face is different from impression management which refers to "the process by which individuals attempt to control the impressions others form of them" [28] (p. 34). Face focuses more on an individual's perceptions of how others may perceive him/her.

Many studies approached face-saving in relation to Chinese consumers' behavior. Jin and Kang [11] found that face-saving had a significantly positive effect on both attitude and purchase intention toward foreign jeans brands among Chinese students, and similar results were found in Jin and Kang's [29] study. However, a study using an Indian consumer sample found no significant relationships between face-saving and attitude towards, nor face-saving and purchase intention for foreign jeans brands [30], implying that face-saving is closely related to consumer behavior in Confucian culture specifically. Considering that the social aspect of face has a profound impact on Chinese consumers' behavior, we argued that understanding the concept of face would be critical to explore sustainable fashion product consumption in China. Because sustainable fashion products are publicly (rather than privately) consumed [14], purchasing and using sustainable fashion products may be associated with Chinese consumers' public self-image enhancement. However, empirical evidence to support whether Chinese consumers' sustainable fashion consumption is influenced by face-saving is still lacking. Thus, this study was aimed at examining the effect of face-saving on Chinese consumers' commitment to purchasing sustainable fashion products.

\subsection{Consumers' Perceived Value of Sustainable Fashion Products}

We applied the theory of perceived value to build our research framework. The early research on perceived value focuses on the tradeoff between gains and costs. Zeithamal [31] defines perceived value as "the consumer's overall assessment of the utility of a product based on perceptions of what is received and what is given" (p. 14). However, later studies argue that perceived value is a much more inclusive concept than "value for price". Woodruff [32] uses the term "customer value" to provide an integrative view for value studies, which refers to "customer's perceived preference for 
and evaluation of those product attributes, attribute performances, and consequences arising from use that facilitate (or block) achieving the customer's goals and purposes in use situations" (p. 142). Built on the consumption value theory [17], Sweeney and Soutar [18] found that functional, emotional and social values are three fundamental dimensions of perceived value. Functional value is defined as the perceived utility for "functional, utilitarian, or physical performance", and emotional value refers to the product's capacity to "arouse feelings or affective states", and social value is the value acquired from the product's association "with one or more specific social groups" [17]. Keller [16] also proposes that functional, experiential and symbolic benefits also come from product or service value. While experiential benefits are related to feelings aroused by using the product or service, symbolic benefits are associated with social imagery [16]. Consistent with previous studies, we employed functional, emotional and social values as three reflective dimensions of general value that consumers can perceive from using the product.

In addition to general value, consumers of sustainable fashion products also perceive the environmental performance of the products they are using. Chen and Chang [19] propose the construct "perceived green value" to delineate values derived from consumers' environmental concerns. They define perceived green value as "a consumer's overall appraisal of the net benefit of a product or service between what is received and what is given based on the consumer's environmental desires, sustainable expectations, and green needs" [19] (p. 505). In this vein, we posited that general product value combined with green value comprised the total perceived utility of sustainable fashion products. While general product value captures the attributes of a product that satisfies consumers' general needs, green value would be a special type of perceived utility aimed at meeting consumers' environmental needs. For example, a product made of organic cotton may protect the user's body from allergies (functional value), and its appealing design would make the user feel good (emotional value). By purchasing a socially desirable product, the user may expect greater social approval (social value), as well as fulfilling environmental needs by consuming less harmful material to the environment, and thus green value can also be satisfied. Thus, both general product value and green value constructs were conceptualized in this study.

\section{Hypotheses Development}

\subsection{Effects of Product Values and Face-Saving on Behavioral Intention}

Consumers' behavioral intention to purchase a product results from positive value delivery [31,32]. That is, the more a product's value is perceived, the higher the likelihood that consumers will purchase that product. Thus, consumers' behavioral intention such as purchasing frequency and amount was examined in this study. Also, as green value is a type of perceived value provided by sustainable products [19], we posited that general product values derived from sustainable fashion items (i.e., functional, emotional and social values) and green values would increase consumers' purchase intention. Thus, we proposed following hypotheses:

Hypotheses 1 (H1). General product value increases intention to purchase sustainable fashion products.

Hypotheses 2 (H2). Green value increases intention to purchase sustainable fashion products.

As fashion products tend to be publicly consumed [14], whether or not to buy sustainable fashion products may be closely related to public self-image enhancement. Particularly, amongst Chinese consumers in a collectivist culture, social norms were found to be more powerful in determining consumers' behavior [11], and face-saving is one of the critical concepts related to social norms. Face-saving oriented individuals try to behave decently and appropriately to maintain a good public image [11,12], and in China, it is a traditional cultural view that people should keep harmony with nature, which makes eco-friendly behavior socially desirable in China [33]. Empirical studies found that consumers in Confucian culture would evaluate green products more favorable because purchasing 
and using green products meets the expectations of others, as well as aligning with social norms, thereby helping to protect one's face $[15,33]$. Also, consumers expect to build reputation and status through the use of sustainable products [9]. As a means of expressing good intentions towards the environment, sustainable fashion products would help Chinese consumers better present themselves in public and thus earn a good reputation. The more consumers are concerned with face-saving, the higher the likelihood that they would commit themselves to sustainable fashion products. Thus, following is hypothesized:

Hypotheses 3 (H3). Face-saving increases intention to purchase sustainable fashion products.

\subsection{Moderating the Role of Face-Saving on the Effects of Product Values}

We posited that the face-saving tendency may act as a moderator in the relationship between perceived value and behavioral intention towards purchasing sustainable fashion products. Consumers in a Confucian culture would evaluate green products more favorable because they strongly feel the need to live up to social expectations [15], and individuals' efforts to save their face are a response to social pressure [34].

From a decision-making perspective [35], consumers search for and evaluate information about a product's attributes before making a purchase. However, consumers in a Confucian culture may simply follow the social pressure to save face in making purchasing decisions about sustainable fashion products instead of carefully evaluating a product's attributes because the purchase needs to meet social expectations [15]. Thus, general product value may become less important in purchase intention when consumers are highly concerned with face-saving. In contrast, green value is associated with socially desirable norms, so the importance of green value becomes greater in purchasing decisions, helping an individual successfully meet the social expectation of protecting the environment [15,33], thus giving the user a good public image. When consumers' face-saving orientation is high, they may want to conform to socially desirable norms by purchasing sustainable fashion products, and thus the importance of green value becomes more salient. Therefore, the following was hypothesized:

Hypotheses 4 (H4). Face-saving negatively moderates the relationship between general product value and intention to purchase sustainable fashion products.

Hypotheses 5 (H5). Face-saving positively moderates the relationship between green value and intention to purchase sustainable fashion products.

\section{Methodology}

\subsection{Preliminary Survey}

We conducted a preliminary study to find out which are the exemplary sustainable fashion brands in Chinese consumers' minds. We first operationalized the concept of sustainable fashion based on an extensive literature review, and obtained a list of fashion brand names through conducting market research and a literature review. Then, 12 students majoring in fashion, textiles and clothing were asked to read the sustainable fashion concept and rate their perceptions of sustainability for each brand name on a seven-point Likert scale $(1=$ strongly disagree, $7=$ strongly agree). Results showed that JNBY $(M=5.58)$, ZUCZUG $(M=5.17)$, MUJI $(M=5.17)$ and CROQUIS $(M=4.75)$ were ranked as the top four sustainable fashion brands. These four brands were thus used as references of sustainable fashion brands in the main survey. 


\subsection{Instruments}

We used a survey method to collect data for hypotheses testing. To help subjects understand the meaning of sustainable fashion, we provided the operationalized definition of the concept of sustainable fashion (i.e., fashion products that benefit, or at least do not harm, our environment and society in their production and consumption processes, and contribute to creating a sustainable future of human beings) with the four exemplary brands found in the primary study. The survey was comprised of items intended to measure perceived consumer value, green value, face-saving, purchase intention, and to gather demographic information. All measurement scales for major constructs were borrowed from previous studies and modified to fit our study's context.

To measure the three dimensions of general product value, namely functional, emotional and social, we adopted 15 items from Sweeney and Soutar's [18] perceived consumer value scale. The items asked respondents to rate their perception of statements such as "[sustainable fashion product] has consistent quality", "would make me feel good" and "would give its owner social approval". The green value of sustainable fashion products was measured using five items from Chen and Chang's [19] study such as "[sustainable fashion product] has more environmental benefit than other products". Face-saving was measured using a three-item scale from Lee's [34] study, and this scale was already being used in fashion consumer studies $[11,29,36]$. An exemplary item is "my decision to buy the product of the sustainable fashion brand would be influenced by whether owning the product of this brand would hurt my reputation with the people who are important to me." Items for general product value, green value and face-saving were measured on a seven-point Likert scale ranging from 1 = strongly disagree to 7 = strongly agree. Moreover, three items from Wulf, Odekerken-Schröder, and Iacobucci's [37] study were used to measure purchase intention. The items were "what percentage of your total expenditures for clothing would you spend on the sustainable fashion brand?" (1-100\%), "of the 10 times you buy clothes, how many times would you select the sustainable fashion brand?" (1-10 times), and "how often would you buy clothes of the sustainable fashion brand compared to other brands that you buy clothes from?" (1 = not at all, $7=$ very often). The present study also had two control variables, altruism and egoism, because these values were found to influence sustainable consumption in previous studies [6,8]. Eleven items measuring these two values were borrowed from Stern et al. [7] and Schwartz [38], asking respondents to rate their perceived importance of statements such as "protecting the environment" and "social power" on a seven-point Likert scale (1 = not important at all, 7 = very important).

The survey questionnaires were first developed in English, and then translated into Chinese. The translation of measurement scale items was translated into English again to find translation equivalence by professionals who were proficient in both English and Chinese [39]. Then, a pilot test was conducted on 38 consumers (18 to 28 years old) to confirm content validity. The main survey was then distributed to target respondents.

\subsection{Data Collection}

The target respondents of the main survey were undergraduate students of Chinese origin in Beijing and Shanghai, the biggest cities in mainland China. We deemed student samples appropriate for use in this study for following reasons: First, the major target consumer groups of the four brands found in the preliminary study are younger consumers, so they may be familiar with these brands. They were believed to have a better understanding of the concept of sustainable fashion practices and thus have the ability to provide adequate responses to the survey questions. Second, Chinese students proved to have a good understanding of the concept of face-saving and they were highly likely to behave in accordance with the face-saving culture [11,29]. Given that the purpose of our study is to increase knowledge about the role of Chinese face-saving in determining sustainable fashion consumption, the cultural homogeneity amongst undergraduate students would benefit our survey $[40,41]$. 
Between late December of 2016 and early January of 2017, Chinese undergraduate students in Shanghai and Beijing were recruited by an online survey company. We set quotas for obtaining a balanced number of responses in terms of gender (i.e., male and female) and cities (i.e., Beijing and Shanghai). All invited subjects could voluntarily participate in the online survey. A total of 503 responses were returned, and 469 responses were analyzed after screening out incomplete and inadequate answers. The sample demographics are summarized in Table 2. Fifty-one percent of our samples were from Shanghai, $49 \%$ from Beijing, and $49.7 \%$ of the total respondents were male and $50.3 \%$ were female. Ages ranged from 18 to 35 years old, and $59.9 \%$ of respondents were between 18 and 24 years old.

Table 2. Sample demographics $(\mathrm{N}=469)$.

\begin{tabular}{|c|c|c|c|c|c|}
\hline & & N (\%) & & & N (\%) \\
\hline \multirow{2}{*}{ Gender } & Male & $233(49.7)$ & Monthly income & $1000 \mathrm{CNY}$ or less & $11(2.3)$ \\
\hline & Female & $236(50.3)$ & & 1001-2000 CNY & $104(22.2)$ \\
\hline \multirow{2}{*}{ City } & Shanghai & $239(51)$ & & 2001-4000 CNY & $166(35.4)$ \\
\hline & Beijing & $230(49)$ & & 4001-6000 CNY & 56 (11.9) \\
\hline \multirow{3}{*}{ Age } & $18-24$ & $281(59.9)$ & & 6001-8000 CNY & $77(16.4)$ \\
\hline & $25-30$ & $127(27.1)$ & & 8001-10,000 CNY & $34(7.2)$ \\
\hline & $31-35$ & $61(13)$ & & More than $10,000 \mathrm{CNY}$ & $21(4.5)$ \\
\hline
\end{tabular}

Note: CNY= China Yuan.

\section{Results}

\subsection{Measurement Model}

Following Anderson and Gerbing's [42] two-step approach, the measurement model was first tested by confirmatory factor analysis (CFA) using maximum likelihood estimation (MLE) in Amos 21.0. Before applying MLE, the normality of construct indicators was assessed. The skew of the indicators ranged from -1.096 to -0.347 , while the kurtosis ranged from -0.572 to 1.788 , which were acceptable ranges for MLE. It is noteworthy that we used summated scores of functional, emotional and social values as the general product value construct for the parsimonious model, and two reverse-wording items of functional value were deleted due to poor factor loadings. The standardized factor loadings and the psychometric properties of the constructs are shown in Table 3.

The data fit the measurement model by meeting the acceptable threshold $\left(\chi^{2}(260)=688.356\right.$, $\chi^{2} / d f=2.648$, CFI (comparative fit index) $=0.943$, TLI (Tucker-Lewis index) $=0.934$, RMSEA (root mean square error of approximation) $=0.059$, SRMR (standardized root mean square residual) $=0.079$ ) [43]. The average variance extracted (AVE) and composite reliability (CR) all exceeded the thresholds of 0.5 and 0.6 , respectively [44], and all items had significant loadings on their constructs. Thus, the measurements in our study were deemed reliable and convergent validity of constructs was satisfactory $[42,44]$. For discriminant validity, we found that there was no correlation higher than 0.9 , and there was no 1.0 appearing in the $95 \%$ confidence interval of every correlation. After that, we constrained one correlation between two constructs to be 1.0 at a time, and found that in every case there was a significant increase in the model $\chi^{2}$ (the smallest $\Delta \chi^{2}=136, p<0.001$ ), indicating the constructs were not perfectly correlated with each other and had good discriminant validity $[42,44]$. The highest correlation appeared to be 0.878 between general product value and green value, but when the correlation between these two constructs was constrained to 1.0, there was a significant increase in model $\chi^{2}\left(\Delta \chi^{2}=136, p<0.001\right)$, supporting good discriminant validity. Given that the two constructs were distinctively conceptualized on a theoretical basis and the discriminant validity was satisfactory, we treated them as two separate constructs for further analysis. 
Table 3. Results of the measurement model.

\begin{tabular}{|c|c|c|}
\hline Constructs & Items & Loadings \\
\hline \multicolumn{3}{|c|}{ Face-saving (AVE $=0.638, C R=0.841)$ Source: $[34]$} \\
\hline \multicolumn{3}{|c|}{$\begin{array}{l}\text { My decision to buy the product of the sustainable fashion brand would be } \\
\text { influenced by: }\end{array}$} \\
\hline FS1 & $\begin{array}{c}\text { whether owning the product of this brand would hurt my reputation with the } \\
\text { people who are important to me }\end{array}$ & 0.836 \\
\hline FS2 & $\begin{array}{l}\text { whether I feel ashamed when people who are important to me see me owning } \\
\text { the product of this brand }\end{array}$ & 0.832 \\
\hline FS3 & $\begin{array}{l}\text { whether I think the brand would improve my reputation to the people who are } \\
\text { important to me }\end{array}$ & 0.724 \\
\hline \multicolumn{3}{|c|}{ Product Value (AVE $=0.816, \mathrm{CR}=0.930$ ) Source: $[18]$} \\
\hline \multicolumn{3}{|c|}{ The product of the sustainable fashion brand: } \\
\hline Functional & (Summate score) & 0.919 \\
\hline FV1 & has consistent quality. & \\
\hline FV2 & is well made. & \\
\hline FV3 & has an acceptable standard of quality. & \\
\hline FV4 & would perform consistently. & \\
\hline Emotional & (Summate score) & 0.915 \\
\hline EV1 & is one that I would enjoy. & \\
\hline EV2 & would make me want to use it. & \\
\hline EV3 & is one that I would feel relaxed about using. & \\
\hline EV4 & would make me feel good. & \\
\hline EV5 & would give me pleasure. & \\
\hline Social & (Summate score) & 0.875 \\
\hline SV1 & would help me to feel acceptable. & \\
\hline SV2 & would improve the way I am perceived. & \\
\hline SV3 & would make a good impression on other people. & \\
\hline SV4 & would give its owner social approval. & \\
\hline \multicolumn{3}{|c|}{ Green Value (AVE $=0.589, \mathrm{CR}=0.878$ ) Source: $[19]$} \\
\hline \multicolumn{3}{|c|}{ The product of the sustainable fashion brand: } \\
\hline GV1 & has environmental functions that would provide very good value for me. & 0.749 \\
\hline GV2 & has environmental performance that would meet my expectation. & 0.774 \\
\hline GV3 & has more environmental concern than other products. & 0.761 \\
\hline GV4 & is environmental friendly. & 0.762 \\
\hline GV5 & has more environmental benefit than other products. & 0.791 \\
\hline \multicolumn{3}{|c|}{ Altruism (AVE $=0.599, \mathrm{CR}=0.913)$ Source: $[7]$} \\
\hline AL1 & Social justice, correcting injustice, care for the weak & 0.785 \\
\hline AL2 & Preventing pollution, conserving natural resources & 0.808 \\
\hline AL3 & Equality, equal opportunity for all & 0.769 \\
\hline AL4 & Unity with nature, fitting into nature & 0.783 \\
\hline AL5 & A world of peace, free of war and conflict & 0.730 \\
\hline AL6 & Respecting the earth, harmony with other species & 0.764 \\
\hline AL7 & Protecting the environment, preserving nature & 0.774 \\
\hline \multicolumn{3}{|c|}{ Egoism (AVE $=0.503, C R=0.801$ ) Source: [7] } \\
\hline EG1 & Social power, control over others, dominance & 0.690 \\
\hline EG2 & Influential, having an impact on people and events & 0.612 \\
\hline EG3 & Wealth, material possessions, money & 0.763 \\
\hline EG4 & Authority, the right to lead or command & 0.762 \\
\hline & Purchase Intention (AVE $=0.668, \mathrm{CR}=0.857$ ) Source: $[37]$ & \\
\hline
\end{tabular}


Table 3. Cont

\begin{tabular}{|c|c|c|}
\hline Constructs & Items & Loadings \\
\hline \multicolumn{3}{|c|}{ In the future: } \\
\hline PI1 & $\begin{array}{l}\text { What percentage of your total expenditures for clothing would you spend in the } \\
\text { sustainable fashion brand? }(1-100 \%)\end{array}$ & 0.784 \\
\hline PI2 & $\begin{array}{l}\text { Of the } 10 \text { times you buy clothes at, how many times would you select the } \\
\text { sustainable fashion brand? (1-10 times) }\end{array}$ & 0.930 \\
\hline PI3 & $\begin{array}{l}\text { How often would you buy clothes of the sustainable fashion brand compared to } \\
\text { other brands that you buy clothes of? }(1=\text { not at all, } 7=\text { very often })\end{array}$ & 0.725 \\
\hline
\end{tabular}

\subsection{Determinants of Behavioral Intention}

The structural equation model was analyzed to test our hypotheses. To examine the main effects of variables on behavioral intention, we first tested the main effect model (Figure 1), and found the model fit the data well $\left(\chi^{2}(260)=688.356, \chi^{2} / d f=2.648\right.$, CFI $=0.943, \mathrm{TLI}=0.934$, RMSEA $=0.059$, SRMR $=0.079)$. In support of $H 1$, general product value increased behavioral intention $\left(\gamma_{1}=0.531\right.$, $p<0.001)$, but the effect of green value on behavioral intention was not significant $\left(\gamma_{2}=-0.181\right.$, $p>0.05$ ), not supporting $\mathrm{H} 2$. We also found a positive effect of face-saving on behavioral intention $\left(\gamma_{3}=0.227, p<0.01\right)$; the more consumers were concerned with saving their face, the more likely they would be to purchase sustainable fashion products. Thus, $\mathrm{H} 3$ was supported. The results also showed that the two control variables, altruism and egoism, had no significant effects on behavioral intention $\left(\gamma_{\text {altruism }}=-0.078, p>0.05 ; \gamma_{\text {egoism }}=0.089, p>0.05\right)$.

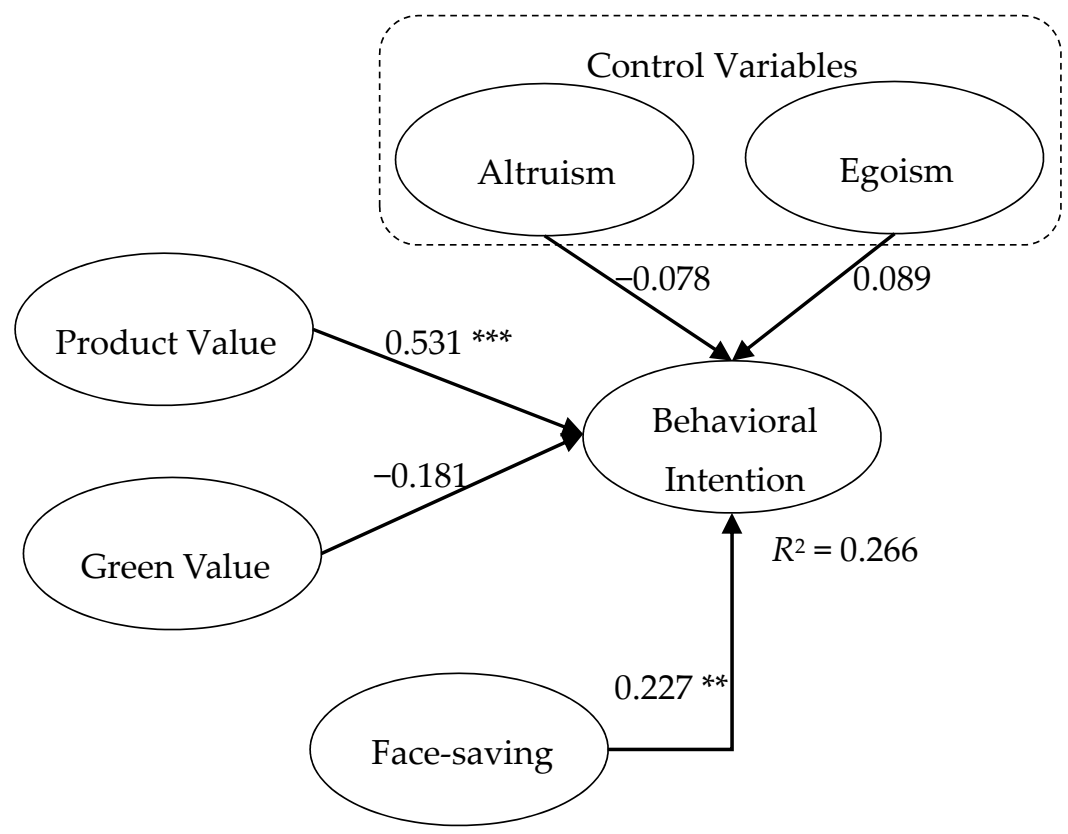

Figure 1. Main effect model (Model 0). All path coefficients were standardized, $R^{2}$ refers to squared multiple correlation. Model fit indices: $\chi^{2}(260)=688.356, \chi^{2} / d f=2.648, C F I=0.943$, TLI $=0.934$, RMSEA $=0.059$, SRMR $=0.079$, Log-likelihood value $=-16,032.436 .{ }^{* *} p<0.01{ }^{* * *} p<0.001$.

\subsection{Moderating Effect of Face-Saving}

We tested the moderating effects of face-saving using the latent moderated structural equations (LMS) approach [45], which has been widely applied in marketing research (e.g., [46]). The LMS approach uses full information of the raw data [45] Compared to other latent interaction analysis 
methods, the LMS approach is advantageous in that it provides an unbiased estimation of interaction effects and standard errors under the normal distribution condition, and it is robust against moderate violation of its distributional assumptions [45]. Furthermore, it has a higher level of statistical power to detect the interaction effect while reducing the Type I error rate [45,47]. Considering satisfactory normality of the data, the application of LMS for estimating the moderating effects of face-saving was deemed highly appropriate in this study.

The results of the structural model with the moderating effects estimated by the LMS approach are presented in Figure 2. Fit indices such as $\chi^{2}$, CFI, TLI, RMSEA, and SRMR were not computed for LMS model estimation. Instead, the LMS approach evaluated the model fit by comparing the main effect model (Model 0) with the moderating effect model (Model 1) using the general likelihood ratio test [45]. If Model 0 fit the data well but represented a significant loss in model fit compared to Model 1 by the likelihood ratio test, it would be assumed that Model 1 fit the data better than Model 0 [45,48]. The -2 log-likelihood statistic for the likelihood ratio test was computed, and the test results showed that the model with the moderating effect (Model 1) fit better than that without the moderating effect (Model 0) $(-2 \log$-likelihood $=14.926, p<0.001)$. Thus, H4 and H5 were supported. In other words, when face-saving is a factor, the effect of perceived product value on consumers' behavioral intention towards purchasing sustainable fashion products becomes weaker $\left(\gamma_{4}=-0.412, p<0.001\right)$, but the effect of green value on behavioral intention becomes stronger $\left(\gamma_{5}=0.339, p<0.01\right)$.

To clearly show the moderated relationships, we plotted the slopes of product value and green value under two conditions of face-saving $(+1 S D$ and $-1 S D)$ in Figures 3 and 4, respectively [48,49]. These results manifested that if consumers are highly concerned with face-saving, general product value became less decisive in their behavior intention to purchase sustainable fashion products, whereas the effect of green value became stronger. The two moderating effects increased the $R^{2}$ of behavioral intention from 0.266 to 0.322 , providing stronger explanatory power than the model containing the main effects only (Model 0). From these findings, we confirmed the moderating effects of face-saving in the relationship between product value and behavioral intention, and between green value and behavioral intention.

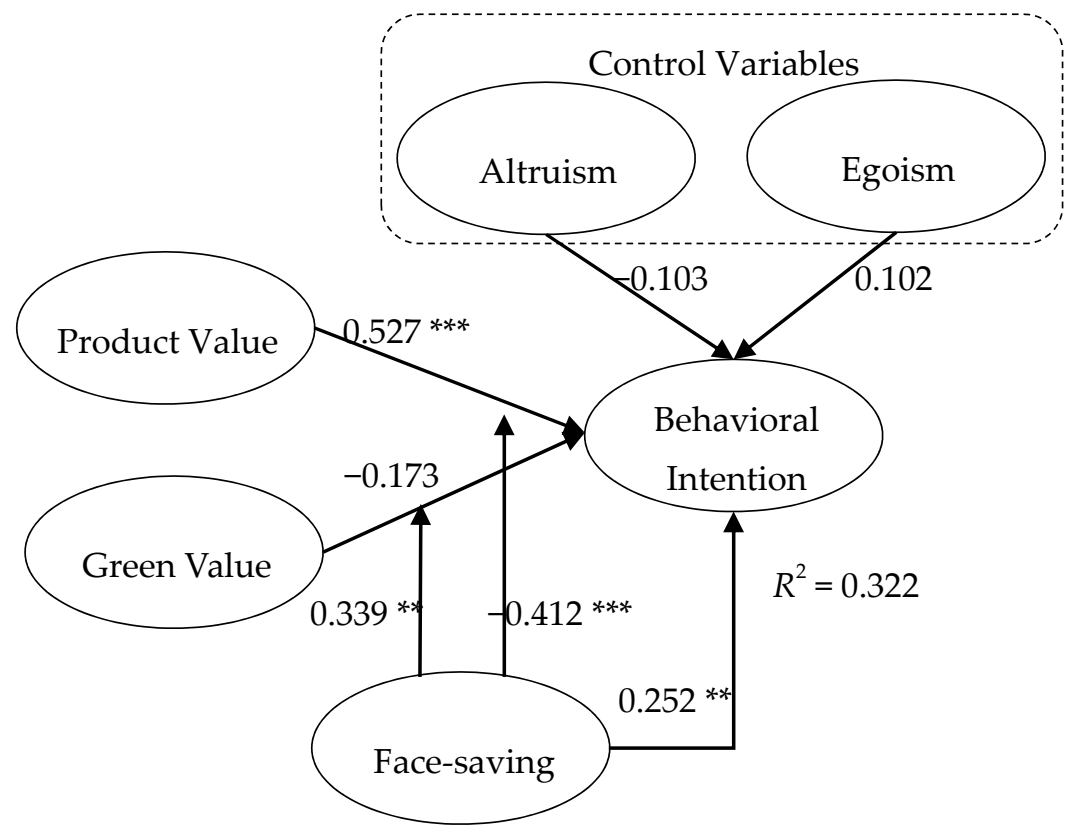

Figure 2. Moderating effect model (Model 1). All path coefficients were standardized, $R^{2}$ refers to squared multiple correlation. Model fit indices: Log-likelihood value $=-16,024.973,-2$ Log-likelihood ratio $=14.926(p<0.001),{ }^{* *} p<0.01,^{* * *} p<0.001$. 


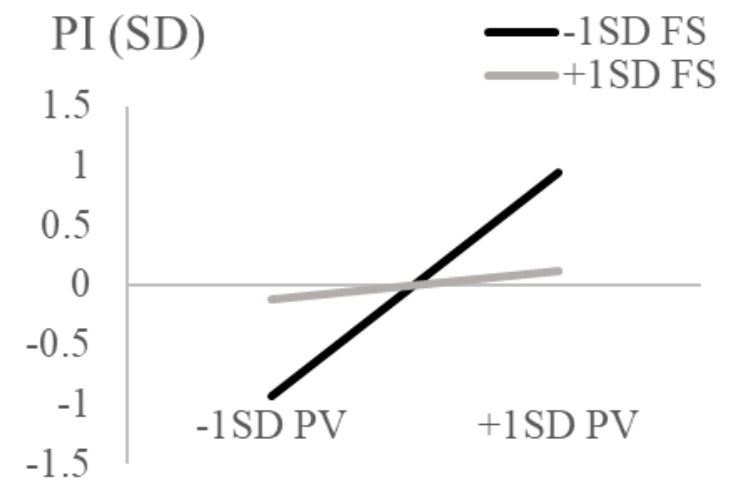

Figure 3. The slopes of product value under two conditioned values of face-saving. PV = Product Value, FS = Face-Saving, BI = Behavioral Intention, $\mathrm{SD}=$ Standard Deviation.

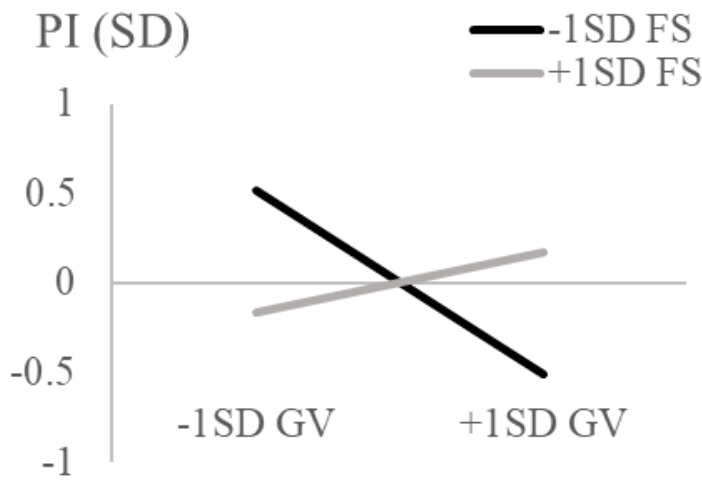

Figure 4. The slopes of green value under the two conditioned values of face-saving. GV = Green Value, FS = Face-Saving, BI = Behavioral Intention, $\mathrm{SD}=$ Standard Deviation.

\section{Discussion}

We empirically tested how Chinese consumers' sustainable fashion purchase intention was driven by both perceived value (i.e., product value and green value) and face-saving orientation. Being consistent with perceived value studies [31,32], the findings proved that general product value had a significant positive effect on Chinese consumers' purchase intentions. However, perceived green value was not a significant indicator for purchase intention in this study. This may be because environmental awareness amongst Chinese consumers may not be pervasive yet, thus they may rarely pay attention to green value. Moreover, Chinese consumers tend to believe it is the government that is responsible for environmental issues [50], so green value might be regarded as less relevant to Chinese consumers.

With the importance of product value, we also found that Chinese consumers' behavioral intention towards purchasing sustainable fashion products was closely related to face-saving values. Though this is the first empirical study to test the relationship between face-saving and sustainable fashion product purchase intention, it also showed a consistent result with the literature which found sustainable product purchases can be driven by self-benefit motives [9,10]. More interestingly, face-saving served as a moderator for purchase intention in the relationships with general product value and green value, respectively. While face-saving reduced the effect of the general product value on purchase intention, it increased the effect of green value. That is, a lower purchase intention in response to general product value would be expected when the face-saving value was activated, whereas a higher purchase intention can be influenced by green value. From these findings, we can conclude that face-saving and general product values are key to increasing Chinese consumers' commitment to purchasing sustainable fashion products. The moderating effects of face-saving on the relationship 
between perceived value and purchase intention were also noteworthy, as this can alter the relative importance of general product value and green value. Chinese consumers considered general product value but not green value when making decisions about purchasing sustainable fashion products, but if they were highly concerned with face-saving, the role of the product's green value becomes more salient.

\section{Implications}

Since the face-saving value can be a crucial factor in promoting sustainable fashion consumption amongst Chinese consumers, marketing managers should make efforts to understand how face-saving can be applied to their promotion strategies and relevant marketing communication. For example, marketers can emphasize face-saving-related benefits through advertising appeals, demonstrating that the product can boost consumers' decent image and present their good intentions in public. By effectively using a sustainable fashion product, Chinese consumers are likely to believe that they can meet social norms and save face, which are important cultural values in China. Although few consumers are motivated by pro-environmental claims, when marketers can effectively utilize face-saving and turn consumers' attention toward sustainable products in fashion, the face-saving value is likely to promote sustainable fashion products, consequently enhancing environmental well-being.

Another implication of the findings is the need to employ different value delivery strategies based on the extent of face-saving potential. As our findings revealed, face-saving had a negative moderating effect on the relationship between general product value and purchase intention. Therefore, for consumers who are less oriented towards face-saving, general product value should be highlighted, because general product value can significantly increase consumers' intention to support sustainable fashion products. This strategy may involve the functional appeal derived from using sustainable fashion products such as using materials that are soft and harmless to users' bodies, emotional value such as feeling good when wearing sustainable products, and social value such as approval from others. On the other hand, for consumers with a higher level of face-saving, the marketing strategy should emphasize a product's green value. That is, managers need to highlight the environmental benefits of their products in the form of green labeling so that customers can easily identify and recognize green values. As for communication strategy, since consumers with a higher level of face-saving are more likely to pay attention to sustainability-related information, the communication of sustainability (i.e., to inform and educate individuals) or ideally the communication for sustainability (i.e., to facilitate societal transformation) [51] can be applied to them, which provides consumers with more deliberate information regarding sustainable development. This may benefit companies' green marketing programs and eventually sustainability of our society.

\section{Future Studies}

Future studies stem from limitations of this study. First, we focused on a student sample in mainland China to investigate the role of face-saving in sustainable fashion consumption. As we argued, the student sample was deemed appropriate, yet future research can be conducted with subjects in different countries with a Confucian culture to help generalize the findings. Second, although we investigated the face-saving effect on sustainable fashion consumption, this effect may not be consistent in different product categories [14]. For example, face-saving would be less influential on the consumption of private household products such as air conditioners and dishwasher detergents because consumers' needs for maintaining a good public self-image becomes less important. Thus, future studies are needed to deepen understanding of the differential effect of face-saving in diverse contexts. Finally, we only considered purchase behavior of sustainable fashion products, but other consumer behaviors like sharing and swapping can also contribute to sustainability by extending the lifecycle of clothes and reducing the waste of material. These behaviors should be further studied in the context of Confucian culture to provide a more comprehensive view of sustainable consumption. 
Acknowledgments: The costs to publish in open access was supported by a grant from the Research Grants Council of the Hong Kong Special Administrative Region, China (PolyU 255033/15B) and the Hong Kong Polytechnic University (F-PP2K).

Author Contributions: Xiaoyong Wei and Sojin Jung developed research ideas based on an extensive literature review and collected data; Xiaoyong Wei analyzed the data and wrote the paper; Sojin Jung provided a thorough review to enhance the overall quality of this paper.

Conflicts of Interest: The authors declare no conflict of interest.

\section{References}

1. China's Garment Market. Available online: http://china-trade-research.hktdc.com/business-news/article/ China-Consumer-Market/China-s-Garment-Market/ccm/en/1/1X000000/1X002L72.htm (accessed on 7 July 2017).

2. Euromonitor: Apparel and Footwear Industry Statistics. Available online: http://www.portal.euromonitor. com.ezproxy.lb.polyu.edu.hk/portal/statistics/rankcountries (accessed on 7 July 2017).

3. Sweeny, G. Fast Fashion Is the Second Dirtiest Industry in the World, Next to Big Oil. Available online: https: / / www.ecowatch.com/fast-fashion-is-the-second-dirtiest-industry-in-the-world-next-tobig--1882083445.html (accessed on 7 July 2017).

4. China Releases National Plan for Implementation of UN Sustainable Development Agenda. Available online: http:/ / english.gov.cn/premier/news/2016/09/20/content_281475446661058.htm (accessed on 7 July 2017).

5. Rapp, J. Eco-Fashion Gets Hip for China's 'Light Green' Consumers. Available online: https://jingdaily. com/eco-fashion-gets-hip-for-chinas-light-green-consumers / (accessed on 7 July 2017).

6. Stern, P.C.; Dietz, T.; Abel, T.; Guagnano, G.A.; Kalof, L.A. value-belief-norm theory of support for social movements: The case of environmentalism. Hum. Ecol. Rev. 1999, 6, 81-97.

7. Stern, P.C. New environmental theories: Toward a coherent theory of environmentally significant behavior. J. Soc. Issues 2000, 56, 407-424. [CrossRef]

8. Akehurst, G.; Afonso, C.; Gonçalves, M.H. Re-examining green purchase behaviour and the green consumer profile: New evidences. Manag. Decis. 2012, 50, 972-988. [CrossRef]

9. Griskevicius, V.; Tybur, J.M.; van den Bergh, B. Going green to be seen: Status, reputation, and conspicuous conservation. J. Personal. Soc. Psychol. 2010, 98, 392-404. [CrossRef] [PubMed]

10. Kareklas, I.; Carlson, J.R.; Muehling, D.D. “I eat organic for my benefit and yours": Egoistic and altruistic considerations for purchasing organic food and their implications for advertising strategists. J. Advert. 2014, 43, 18-32. [CrossRef]

11. Jin, B.; Kang, J.H. Face or subjective norm? Chinese college students' purchase behaviors toward foreign brand jeans. Cloth. Text. Res. J. 2010, 28, 218-233. [CrossRef]

12. Kim, J.Y.; Nam, S.H. The concept and dynamics of face: Implications for organizational behavior in Asia. Organ. Sci. 1998, 9, 522-534. [CrossRef]

13. Brown, P.; Levinson, S.C. Politeness: Some Universals in Language Usage; Cambridge University Press: Cambridge, UK, 1987.

14. Bearden, W.O.; Etzel, M.J. Reference group influence on product and brand purchase decisions. J. Consum. Res. 1982, 9, 183-194. [CrossRef]

15. Cho, Y.N.; Thyroff, A.; Rapert, M.I.; Park, S.Y.; Lee, H.J. To be or not to be green: Exploring individualism and collectivism as antecedents of environmental behavior. J. Bus. Res. 2013, 66, 1052-1059. [CrossRef]

16. Keller, K.L. Conceptualizing, measuring, and managing customer-based brand equity. J. Mark. 1993, 57, 1-22. [CrossRef]

17. Sheth, J.N.; Newman, B.I.; Gross, B.L. Why we buy what we buy: A theory of consumption values. J. Bus. Res. 1991, 22, 159-170. [CrossRef]

18. Sweeney, J.C.; Soutar, G.N. Consumer perceived value: The development of a multiple item scale. J. Retail. 2001, 77, 203-220. [CrossRef]

19. Chen, Y.S.; Chang, C.H. Enhance green purchase intentions: The roles of green perceived value, green perceived risk, and green trust. Manag. Decis. 2012, 50, 502-520. [CrossRef]

20. Elkington, J. Cannibals with Forks: The Triple Bottom Line of 21st Century Business; New Society: Gabriola Island, BC, Canada, 1998. 
21. Goworek, H.; Fisher, T.; Cooper, T.; Woodward, S.; Hiller, A. The sustainable clothing market: An evaluation of potential strategies for UK retailers. Int. J. Retail Distrib. Manag. 2012, 40, 935-955. [CrossRef]

22. Joergens, C. Ethical fashion: Myth or future trend? J. Fash. Mark. Manag. Int. J. 2016, 10, 360-371. [CrossRef]

23. Niinimäki, K. Eco-clothing, consumer identity and ideology. Sustain. Dev. 2010, 18, 150-162. [CrossRef]

24. Lundblad, L.; Davies, I.A. The values and motivations behind sustainable fashion consumption. J. Consum. Behav. 2016, 15, 149-162. [CrossRef]

25. Lee, N.; Choi, Y.J.; Youn, C.; Lee, Y. Does green fashion retailing make consumers more eco-friendly? The influence of green fashion products and campaigns on green consciousness and behavior. Cloth. Text. Res. J. 2012, 30, 67-82. [CrossRef]

26. Liu, X.; Wang, C.; Shishime, T.; Fujitsuka, T. Sustainable consumption: Green purchasing behaviours of urban residents in China. Sustain. Dev. 2012, 20, 293-308. [CrossRef]

27. Ho, D.Y.F. On the concept of face. Am. J. Social. 1976, 81, 867-884. [CrossRef]

28. Leary, M.R.; Kowalski, R.M. Impression management: A literature review and two-component model. Psychol. Bull. 1990, 107, 34. [CrossRef]

29. Jin, B.; Kang, J.H. Purchase intention of Chinese consumers toward a US apparel brand: A test of a composite behavior intention model. J. Consum. Mark. 2011, 28, 187-199. [CrossRef]

30. Son, J.; Jin, B.; George, B. Consumers' purchase intention toward foreign brand goods. Manag. Decis. 2013, 51, 434-450. [CrossRef]

31. Zeithaml, V.A. Consumer perceptions of price, quality, and value: A means-end model and synthesis of evidence. J. Mark. 1988, 52, 2-22. [CrossRef]

32. Woodruff, R.B. Customer value: The next source for competitive advantage. J. Acad. Mark. Sci. 1997, 25, 139-153. [CrossRef]

33. Chan, R.Y. Determinants of Chinese consumers' green purchase behavior. Psychol. Mark. 2001, 18, $389-413$. [CrossRef]

34. Lee, C. Modifying an American consumer behavior model for consumers in Confucian culture: The case of Fishbein behavioral intention model. J. Int. Consum. Mark. 1991, 3, 27-50. [CrossRef]

35. Engel, J.F.; Blackwell, R.D.; Miniard, P.W. Consumer Behavior, 8th ed.; The Dryden Press: New York, NY, USA, 1995.

36. Jin, B.; Son, J. Face saving, materialism, and desire for unique apparel products: Differences among three Asian countries. J. Text. Inst. 2014, 105, 304-313. [CrossRef]

37. Wulf, K.D.; Odekerken-Schröder, G.; Iacobucci, D. Investments in consumer relationships: A cross-country and cross-industry exploration. J. Mark. 2001, 65, 33-50. [CrossRef]

38. Schwartz, S.H. Are there universal aspects in the structure and contents of human values? J. Soc. Issues 1994, 50, 19-45. [CrossRef]

39. Douglas, S.P.; Craig, C.S. International Marketing Research, 3rd ed.; John Willey \& Sons, Ltd.: Chichester, UK, 2005.

40. Greenberg, J. The college sophomore as guinea pig: Setting the record straight. Acad. Manag. Rev. 1987, 12, 157-159.

41. Lynch, J.G., Jr. Theory and external validity. J. Acad. Mark. Sci. 1999, 27, 367-376. [CrossRef]

42. Anderson, J.C.; Gerbing, D.W. Structural equation modeling in practice: A review and recommended two-step approach. Psychol. Bull. 1988, 103, 411-423. [CrossRef]

43. Hu, L.T.; Bentler, P.M. Cutoff criteria for fit indexes in covariance structure analysis: Conventional criteria versus new alternatives. Struct. Equ. Model. Multidiscip. J. 1999, 6, 1-55. [CrossRef]

44. Bagozzi, R.P.; Yi, Y. On the evaluation of structural equation models. J. Acad. Mark. Sci. 1988, 16, 74-94. [CrossRef]

45. Klein, A.; Moosbrugger, H. Maximum likelihood estimation of latent interaction effects with the LMS method. Psychometrika 2000, 65, 457-474. [CrossRef]

46. Korschun, D.; Bhattacharya, C.B.; Swain, S.D. Corporate social responsibility, customer orientation, and the job performance of frontline employees. J. Mark. 2014, 78, 20-37. [CrossRef]

47. Jackman, M.G.A.; Leite, W.L.; Cochrane, D.J. Estimating latent variable interactions with the unconstrained approach: A comparison of methods to form product indicators for large, unequal numbers of items. Struct. Equ. Model. Multidiscip. J. 2011, 18, 274-288. [CrossRef] 
48. Maslowsky, J.; Jager, J.; Hemken, D. Estimating and interpreting latent variable interactions: A tutorial for applying the latent moderated structural equations method. Int. J. Behav. Dev. 2015, 39, 87-96. [CrossRef] [PubMed]

49. Aiken, L.S.; West, S.G. Multiple Regression: Testing and Interpreting Interactions; Sage Publications: Newbury Park, CA, USA, 1991.

50. Martina, M. Sustainable Consumption on the Fringe in China: Study. Available online: http://www.reuters. com/article/us-china-consumption-sustainability-idUSTRE73H1P320110418 (accessed on 7 July 2017).

51. Newig, J.; Schulz, D.; Fischer, D.; Hetze, K.; Laws, N.; Lüdecke, G.; Rieckmann, M. Communication regarding sustainability: Conceptual perspectives and exploration of societal subsystems. Sustainability 2013, 5, 2976-2990. [CrossRef]

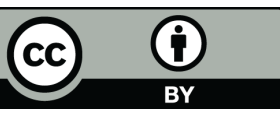

(C) 2017 by the authors. Licensee MDPI, Basel, Switzerland. This article is an open access article distributed under the terms and conditions of the Creative Commons Attribution (CC BY) license (http:/ / creativecommons.org/licenses/by/4.0/). 